\title{
Application of Hill's criteria of causation to shaken baby syndrome: Further evidence that questions the existence of shaken baby syndrome
}

\author{
Marvin Miller \\ Department of Pediatrics and Biomedical Engineering, Wright State University Boonshoft School of Medicine, Dayton, Ohio, \\ USA. \\ Correspondence: Marvin Miller, M.D. Address: Dayton Children's Hospital, 1 Children's Plaza, Department of Medical \\ Genetics, Dayton, Ohio 45404, USA. Email: millerme@childrensdayton.org \\ Received: May 28, 2015 \\ Accepted: June 30, 2015 \\ Online Published: July 6, 2015 \\ DOI : $10.5430 /$ jbei.v1n1p1 \\ URL: http://dx.doi.org/10.5430/jbei.v1n1p1
}

\section{Abstract}

Background: Controversy about the existence of shaken baby syndrome persists. This diagnosis was once routinely accepted in the infant who presents with the triad - unexplained subdural hematoma, retinal hemorrhages, and neurologic dysfunction. However, a critical examination of the relevant biomechanical, biologic, and clinical findings in the infant with the triad now suggests shaken baby syndrome may not exist, and medical mimics of this entity may have been missed.

Methods: The author performed a Hill's analysis of causation using 9 criteria typically evaluated in such an assessment using a Google Scholar search of the medical literature for relevant information on shaken baby syndrome.

Results: None of the 9 criteria were fulfilled in the analysis.

Conclusion: Using a well-accepted analysis for evaluating whether a specific event (shaking) leads to a specific outcome (the triad), there was no compelling evidence that shaking causes the triad.

\section{Key words}

Hill analysis of causation, Shaken baby syndrome, Child abuse, Abusive head trauma, Non-accidental head injury

\section{I ntroduction}

Great controversy exists regarding whether shaken baby syndrome (SBS) is a real clinical condition, and there is great concern that those who make this diagnosis often miss mimics of SBS (The term abusive head trauma [AHT; also called Non Accidental Head Injury] was introduced by the American Academy of Pediatrics Committee on Child Abuse and Neglect in 2009 to replace the term SBS. The motivation for this change in terminology appears to be a desire to include other injury mechanisms that could cause the triad that were previously not appreciated. The term SBS, however, is still commonly used in both the lay and medical literature.) ${ }^{[1-3]}$. Until recently, it has been dogma that vigorously shaking an infant can cause the triad (subdural hematoma, retinal hemorrhage, and neurologic dysfunction such as seizures or an acute life-threatening event). While many pediatricians, child abuse and pediatric specialists, and prosecutors of child abuse cases still assert its existence, several recent events have indirectly cast further doubt on its validity including the following: 
1) Multiple, successful post-convictions appeals and rulings overturning previous guilty verdicts ${ }^{[4]}$.

2) Declaration by Dr. Norman Guthkelch that his original description of whiplash injuries in no way validates the existence of SBS ${ }^{[5,6]}$.

3) Declaration by the Swedish Supreme Court that the science behind SBS is uncertain which quashed the conviction of a man who was imprisoned for allegedly causing SBS. This decision will likely result in the retrial of other SBS cases in Sweden ${ }^{[7]}$.

Epidemiologists have not been actively involved in this heated issue; it has mainly been the interest of clinicians, biomechanicians, and prosecutors. But epidemiologists have a powerful tool for evaluating whether a specific event (shaking an infant) can produce a specific outcome (the triad), namely Hill's criteria for judging causation ${ }^{[8]}$.

In 1965 epidemiologist Austin Bradford Hill published criteria which he thought could help determine the likelihood that event A could produce outcome B. These criteria are shown in the Table, and herein is a review of these criteria as they apply to SBS. Biomechanical considerations are highly relevant to the discussion.

Table. Summary of Hill's Criteria as They Relate to SBS

\begin{tabular}{|c|c|c|}
\hline Criteria & Observations & Fulfills Criteria \\
\hline Temporal relationship & $\begin{array}{l}\text { Shaking is rarely admitted/observed in }>50,000 \text { cases } \\
\text { in USA over past } 40 \text { years }\end{array}$ & No \\
\hline Strength of association & Shaking inferred; No statistical studies & No \\
\hline Biologic gradient & $\begin{array}{l}\text { Not consistent with biofidelic models - threshold for } \\
\text { causing brain injury by shaking alone not reached; No } \\
\text { neck injury or chest bruising which would be expected }\end{array}$ & No \\
\hline Coherence & $\begin{array}{l}\text { Not consistent with experimental animal studies or } \\
\text { biofidelic human models }\end{array}$ & No \\
\hline Biologic plausibility & $\begin{array}{l}\text { Not consistent with neuropathology which shows } \\
\text { hypoxic injury, not traumatic injury }\end{array}$ & No \\
\hline Biomechanical plausibility & $\begin{array}{l}\text { Not consistent with experimental animal/biofidelic } \\
\text { model findings }\end{array}$ & No \\
\hline Consideration of alternative explanations & $\begin{array}{l}\text { Multiple other causes of the triad; Medical mimics that } \\
\text { can cause the triad are not always considered }\end{array}$ & No \\
\hline Specificity & $\begin{array}{l}\text { There are multiple known causes of the triad - thus not } \\
\text { informative }\end{array}$ & NI* \\
\hline Experimental evidence & $\begin{array}{l}\text { No evidence that national awareness of the potential } \\
\text { dangers of shaking has decreased the incidence of } \\
\text { SBS; There has actually been an increase in the } \\
\text { frequency of SBS }\end{array}$ & No \\
\hline Replication of findings & $\begin{array}{l}\text { Biofidelic model findings and autopsy findings agree } \\
\text { with each other: These findings suggest shaking does } \\
\text { not cause the triad }\end{array}$ & No \\
\hline
\end{tabular}

* Not informative

\section{Methods}

The author ascertained relevant articles from the medical literature using Google Scholar searches for each of the 9 Hill criteria. The terms "shaken baby syndrome" and "abusive head trauma" were combined with the following 9 terms and terms of similar meaning:

1) Temporal relationship 
2) Strength of association

3) "Biomechanics" and "Dose-response effect"

4) Coherence

5) Biologic plausibility

6) Analogy

7) Specificity

8) Experimental evidence

9) Replication of findings

The references in these articles were also used to obtain relevant articles. The information in these articles was evaluated for each of the 9 criteria, and the author judged whether each specific category fulfilled Hill's criteria.

\section{Results}

Below is the analysis for each of the 9 criteria. The Table summarizes the findings related to each criterion, and the conclusion of whether each criterion was fulfilled. In addition to biologic plausibility, the author added biomechanical plausibility to category 6, as this is a relevant issue in SBS. In 8 of the 9 criteria, the author did not believe there was evidence to support the Hill criteria. There was one criterion, specificity, that the author concluded could not be applied to this issue.

1) Temporal relationship: Exposure always precedes the outcome, i.e. shaking always precedes the triad.

In many cases of alleged SBS there is no history of a parent or caregiver admitting to shaking the infant. A review of SBS cases shows that parents/caregivers accused of causing SBS rarely report that the infant was violently shaken. In spite of an estimated 50,000 cases of alleged cases of SBS since the diagnosis was first described in the early 1970s (using an estimate of 1,200 cases/year, a conservative estimate) there are few witnessed cases of shaking causing SBS and no video-taped SBS events ${ }^{[9,10]}$. Sometimes there is an admission of shaking the infant by a parent/caregiver in the setting of apnea or an acute life-threatening event in an effort to resuscitate the infant, but this is gentle shaking that most would think insignificant. Some confessions to shaking an infant who presents with the triad may be coerced ${ }^{[11]}$.

Leestma reviewed the literature from 1969-2001 and found 324 cases of SBS in which 54 individuals admitted to shaking the infant ${ }^{[10]}$. In 11 cases there was no evidence of impact, suggesting it was pure shaking that caused the abnormalities. Leestma notes that most of the cases were without a confession, and the diagnosis was made by the judgment of a multidisciplinary panel.

2) Strength of association: The association of shaking and the triad is compelling and convincing based on appropriate statistical analysis.

Given that shaking is rarely given in the history, there is a weak association of admitted shaking and SBS. While shaking is often identified as the mechanism causing the triad, the medical-legal system typically infers it, and rarely is violent shaking observed or admitted. As noted, some confessions, when admitted, were coerced. Lee studied parenting behaviors of 1,248 fathers for their 3 year olds as reported by mothers. In 24 instances shaking was reported as a parenting behavior by the father, but there was no reported evidence of SBS in these 24 infants ${ }^{[12]}$. Likewise, Runyan notes the highly variable frequencies of shaking young infants in various cultures and countries as part of disciplinary practices. This rate of infant shaking is as high as $42 \%$ in the urban slums of India, but without apparent evidence of SBS ${ }^{[13]}$. 
Thus, there has been no statistical analysis of any large, unbiased series to meet this criterion.

3) Biologic gradient (dose-response effect): An increasing amount of dose (shaking) increases the risk (of developing the triad).

a) Human

It is not possible to study this ethically in the human.

b) Experimental animals

The magnitude of rotational acceleration needed to produce SDH have been studied by Ommaya et al. in the monkey who found that extrapolation of their findings to the human estimated that a conservative minimal rotational acceleration to cause traumatic shaking injury would be about 4,000 radian/sec2 ${ }^{[14]}$. This threshold value for causing serious intracranial injury from rotational acceleration of the head is far higher than that found in the 3 studies of shaking biofidelic human dolls, as discussed below ${ }^{[14]}$. Ommaya also found that 11 of the 19 adult monkeys had neck injuries. Adult monkeys have greater neck musculature than human infants, yet neck injury is conspicuously absent in most cases of SBS.

c) Biofidelic models

Three studies of biofidelic dolls have evaluated the magnitude (dose) of rotational acceleration that results from shaking and from short falls ${ }^{[15-17]}$. Each study showed that the rotational acceleration generated by shaking a biofidelic doll is far below the threshold for causing brain injury as determined by Ommaya ${ }^{[14]}$. The rotational accelerations (radian/sec2) generated by shaking in the 3 studies were the following: Duhaime $=1,139$, Prange $=2,600$ (maximal in which head hit back and chest), and Lloyd = 1,068.

Moreover, the rotational accelerations generated on a biofidelic doll from a short fall are far greater than those generated from shaking ${ }^{[15-18]}$. Over the years SBS proponents have argued that short falls cannot cause the triad in spite of the compelling and consistent science that short falls produce far greater rotational head acceleration than vigorous shaking ${ }^{[19]}$.

4) Coherence (consistency with other knowledge): A conclusion that shaking causes the triad does not contradict generally accepted ideas and knowledge.

Bandak has provided compelling evidence that at a magnitude (dose) of force to cause intracranial brain damage, severe neck injury with cervical spine fractures/dislocations would be expected ${ }^{[20,21]}$. Noteworthy was the presence of neck injuries in 11 of 19 adult monkeys in the Ommaya studies ${ }^{[14]}$. Adult monkeys have greater neck musculature than human infants, and thus neck injuries would be expected in an infant, if this finding is extrapolated to the human infant. The conspicuous absence of neck injury in most cases of alleged SBS raises serious doubt as to whether violent shaking occurred.

Intuitively, the physical forces required to disrupt the integrity of skin capillaries to cause a bruise would be exceeded if an adult violently shook an infant while holding the infant. Thus, bruising on the external chest wall from the finger tips holding the chest wall tightly while shaking the infant should be found in many of these cases, yet is conspicuously absent ${ }^{[22]}$.

5) Plausibility: The proposed relationship between shaking and the triad is plausible based on current biologic and biomechanical knowledge.

a) Biologic/Pathology at Autopsy 
SBS proponents posit that the SDHs in SBS result from the tearing of a bridging vein that traverses through the dural membrane and that the damage to neurons is traumatic in origin ${ }^{[23]}$. However, there are compelling gross and microscopic observations from postmortem examinations of infants who die from alleged SBS that are not consistent with this idea.

\section{Gross observations}

Most SDHs associated with SBS are thin and bilateral. SBS proponents believe that the SDHs in SBS result from the tearing of a bridging vein that traverses through the dural membrane ${ }^{[23]}$. However, it would be expected that the tearing of a bridging vein would lead to bleeding far in excess of what is seen in thin SDHs, and bridging vein tears/ruptures are rarely ever found in alleged victims of SBS at autopsy ${ }^{[24]}$.

\section{Microscopic observations}

Geddes et al. studied the neuropathology of infants alleged to have died from SBS. Rather than finding axonal injury, which would suggest a traumatic event, they found changes that suggested these infants died from severe hypoxia which included intradural hemorrhaging, which they thought explained the thin dural hemorrhage that is often found in alleged cases of SBS ${ }^{[25-27]}$. The novel finding of intradural hemorrhage in many of her cases was also found by Cohen and Scheinburg ${ }^{[28,29]}$. These pathologic observations strongly suggest that the pathogenesis of most cases of the triad relate to a primary insult associated with hypoxia. Hypoxia leads to intradural/thin subdural hemorrhage which leads to inflammatory changes in the brain with increased intracranial pressure (ICP). The increased ICP leads to the neurologic dysfunction and retinal vein obstruction that is the basis of the retinal hemorrhages.

SBS proponents do not agree with this pathogenesis, and are adamant that it is shaking that causes the SDH and shaking that causes the retinal hemorrhages. However, there are other observations that support the notion that hypoxia can cause SDH. In young infants with congenital heart disease associated with hypoxia, SDH can be appreciated by head MRI both before and after surgical correction of the congenital heart disease ${ }^{[30]}$. Dysphagic choking associated with hypoxia can also lead to the triad ${ }^{[31]}$.

\section{b) Biomechanical}

The findings from the 3 studies using biofidelic dolls and Bandak's calculations for the forces needed to cause neck injury - which are far below those needed to cause intracranial injury -indicate violent shaking is not a plausible explanation in cases of the triad ${ }^{[15-17,20,21]}$.

6) Consideration of Alternative Explanations: Are there other causes of the triad that are sufficiently excluded in the evaluation of the infant with the triad.

There are medical conditions and diseases that have been described since the initial description of SBS in the early 1970s that can cause the triad and are summarized in several articles ${ }^{[17,32]}$. Barnes has summarized the differential diagnosis of SDH from a pediatric neuroradiologist perspective (often associated with RHs), and Lantz has reported on the differential diagnosis of retinal hemorrhages (often associated with SDH) ${ }^{[33,34]}$. Notably, the notion that hypoxia and increased intracranial pressure causes the RHs in the triad, and not traumatic vitreous traction, is supported by the findings in high altitude retinopathy ${ }^{[35]}$.

Thus, the triad can be seen in multiple different clinical settings. The reflexive diagnosis of child abuse without consideration of these alternative diagnoses can lead to misdiagnosis and devastating and irreparable consequences for the family ${ }^{[36]}$. Relatively common medical mimics of the triad include ${ }^{[37,38]}$ :

- Short falls 
- Cortical vein/Sinus thrombosis

- Rebleeding and expansion of a small SDH from the birth process

- Increased extra-axial fluid spaces which can cause a SDH with minimal forces or spontaneously

Six infants with the above mimics were recently reported in which child abuse was initially diagnosed. In all cases the parents denied wrongdoing, and each infant was returned to the parents after legal proceedings. In follow-up there was no evidence of child maltreatment suggesting that these cases were unlikely child abuse ${ }^{\text {[39] }}$. Short falls were once dismissed by SBS proponents as benign events in which the physical force of a short fall was insufficient to cause intracranial injury. However, as previously noted, short falls produce an angular acceleration far greater than shaking, and the series of cases of short falls associated with the triad compiled by Plunkett unequivocally demonstrated that short falls could cause the triad ${ }^{[40]}$. Finally, uncommon genetic disorders such as glutaric aciduria - type 1 or Menkes disease can mimic SBS and if not recognized, can have devastating outcomes as in the case of Daniel Crow and Menkes disease ${ }^{[41]}$.

7) Specificity: Does a single cause (shaking) produce a specific outcome (the triad)?

This is perhaps the weakest of the Hill criteria as outcomes can have multiple different causations. It is not possible to apply this criterion, because there are multiple different causes of the triad.

8) Experimental evidence: Are there experimental interventions or programs promoting awareness of the potential dangers of shaking that can prevent SBS?

In 2005 a pilot program suggested that increased public awareness of the dangers of shaking an infant can prevent cases of SBS ${ }^{[42]}$. This prompted many states to pass laws mandating discussion of shaking with parents at the time a newborn's discharge from the nursery ${ }^{[43]}$. In spite of this widespread national effort to prevent SBS through these awareness programs, the incidence of SBS in the USA has slightly increased from 31.2 cases/100,000 children in 2000 to 33.4 cases/100,000 infants in $2009^{[44]}$. Moreover, the total combined rates of SBS-related hospitalizations, ED visits, and deaths increased 50\% from about 521/100,000 USA population in 2001 to $823 / 100,000$ USA population in $2010^{[45]}$.

9) Replication of findings: There are multiple studies using different approaches that reach the same conclusion.

There are no replication of studies that support the existence of SBS, although there are abundant studies that infer its existence by using the triad as a default diagnosis for SBS. There are, however several replication of findings studies using different approaches that conclude shaking is unlikely a cause of the triad. The biomechanical studies in biofidelic models previously discussed have been replicated in 3 studies with similar results - the rotational acceleration generated by shaking is insufficient to cause intracranial pathology. Likewise, the 2 autopsy studies of alleged SBS infants previously discussed show gross and microscopic findings that are more consistent with hypoxia than trauma.

\section{Medical literature that supports the diagnosis of shaken baby syndrome}

These multiple Google Scholar searches generated many articles that indirectly infer the existence of SBS. These articles used the triad as the basis for diagnosing shaken baby syndrome and evaluated some aspect of SBS - for example, incidence, who the alleged perpetrator was, what time of the year the infant presented, prognostic indicators, various demographics such as race and ethnicity, and many others. In most articles the diagnosis SBS was affirmed by a multidisciplinary team or a confession. There was typically little consideration for mimics of shaken baby syndrome ${ }^{[46-49]}$. 
In spite of this voluminous literature, there were few substantive and convincing studies that provided scientific evidence that SBS existed. These articles merely used the triad as a finding that was believed to be highly specific for SBS.

\section{Discussion}

The results of this Hill's causation analysis indicate there is weak support that shaking alone can cause the triad. The first Hill criterion, temporal relationship between the putative cause and outcome, is an essential criterion. There are few documented observations of shaking in over 50,000 alleged SBS events over the past 40 years. This suggests that some cases of alleged SBS are not from shaking, but are likely from medical mimics of SBS or from head trauma, either accidental (short falls) or intentional. A head MRI showing a subdural hematoma does not ipso facto prove an intent to harm, yet this is what SBS proponents have asserted over the past 40 years ${ }^{[34]}$. The highly revealing biomechanical and pathological studies that discount the existence of SBS were not performed until more than 15 years after the initial description of SBS. Had these compelling studies been available in the early 1970s, this embarrassing chapter in the history of pediatrics might have been avoided. However, by the time these revealing studies were published, SBS had become entrenched in pediatric medicine as a clinical diagnosis. How has such an important diagnosis like SBS existed for so many years without any real scientific legitimacy? The author offers the following hypothesis:

After the initial descriptions of young infants with the triad in the 1970s, Guthkelch and Caffey suggested shaking/ whiplash as a possible explanation for causing the triad ${ }^{[50,51]}$. This was clearly speculation as there was no biomechanical or pathological information at that time to bolster shaking as the sole cause of the triad. However, Henry Kempe's description of the battered child syndrome in 1962 offered a tempting linkage to the explanation of this disorder -child abuse ${ }^{[52]}$. The pediatric community immediately adopted this speculative pathogenesis as the cause of the triad, and with the growth of the child abuse medicine subspecialty, this community of physicians teamed up with pediatric radiologists and pediatric ophthalmologists and zealously defended SBS as a bon fide diagnosis.

SBS proponents often promote their position as necessarily correct due to:

1) The 700 articles written about SBS since it was initially described

2) Many professional organizations that support its existence since it was originally described

3) Many research grants that have been funded to study SBS.

However all of these self-serving assertions are meaningless if the original assumptions about SBS over 40 years ago were erroneous. Making the same mistake over and over again is not progress. Notably, Dr. Guthkelch has adamantly asserted that his 1971 observation in no way affirms that shaking causes the triad ${ }^{[5,6]}$.

The present analysis comports with Donohue's critical review of the evidence based medicine studies published between1966-1998 that support SBS as a real condition ${ }^{[53]}$. Donohue concluded that "the evidence for SBS appears analogous to an inverted pyramid, with a small database (most of it poor-quality original research, retrospective in nature, and without appropriate control groups) spreading to a broad body of somewhat divergent opinions.” Acres and Morris reported a Hill's causation analysis on the pathogenesis of retinal hemorrhages and subdural hematoma in accidental head injury in infancy that concentrated on the Geddes work without consideration of some of the issues detailed in the present analysis such as temporal relationship information and biomechanical considerations ${ }^{[54]}$. Their conclusion is similar to that of Donohoe and the present article - marginal scientific support for the existence of shaken baby syndrome. Acres and Morris emphasized the concept of hypoxic injury being the major cause of the triad, and not traumatic injury which would be expected if shaking caused the injury. 
In conclusion, this Hill's causation analysis seriously questions whether SBS truly exists, and posits that cases of the triad previously diagnosed as caused by shaking likely have a different etiology. Child abuse is still a possible explanation in such cases of the triad, but shaking alone is highly unlikely to cause the triad - some type of impact would be expected. Tragically, the reflexive diagnosis of SBS in the past has likely missed some of the medical mimics of SBS.

\section{Acknowledgements}

We acknowledge Eric Gershon for his critical review of the manuscript.

\section{References}

[1] Narang S. A Daubert Analysis of Abusive Head Trauma/Shaken Baby Syndrome. Hous. J. Health L. \& Pol'y. 2011; 11: 539-60. http://dx.doi.org/10.2139/ssrn.1919054

[2] David AM. Shaken Baby Syndrome, Abusive Head Trauma, and Actual Innocence: Getting it Right. K. A. Findley, P. D. Barnes, and W. Squier, co-authors. Hous. J. Health L. \& Pol'y. 2012; 12: 209-312.

[3] Christian CW, Block R. Abusive head trauma in infants and children. Pediatrics. 2009; 123: 1409-11. PMid:19403508. http://dx.doi.org/10.1542/peds.2009-0408

[4] http://www.theatlantic.com/health/archive/2014/11/how-can-doctors-be-sure-a-babys-beenshaken/382632/?single_page=true

[5] Guthkelch AN. Problems of infant retino-dural hemorrhage with minimal external injury. Hous. J. Health L. \& Pol'y. 2012; 12: 201-08.

[6] Guthkelch AN. 2015 Arthur Norman Guthkelch: An Autobiographical Note. Argument \& Critique, Special Edition, June. http://www.argumentcritique.com/special-edition.html

[7] http://www.thelocal.se/20130109/45504

[8] Hill AB. The environment and disease: Association or causation? Proc R Soc Med. 1965; 58: 295-300. PMid:14283879.

[9] Keenan HT, Runyan DK, Marshall SW, et al. A population-based comparison of clinical and outcome characteristics of young children with serious inflicted and noninflicted traumatic brain injury. Pediatrics. 2004; 114: 633-9. PMid:15342832. http://dx.doi.org/10.1542/peds.2003-1020-L

[10] Leestma JE. Case analysis of brain-injured admittedly shaken infants: 54 Cases, 1969-2001. Am J Forensic Pathol. 2005; 26: 199-212. http://dx.doi.org/10.1097/01.paf.0000164228.79784.5a

[11] Leestma JE. "Shaken baby syndrome”: Do confessions by alleged perpetrators validate the concept. Journal of American Physicians and Surgeons. 2006; 11: 14-26.

[12] Lee SJ, Kim J, Taylor CA, et al. Profiles of Disciplinary Behaviors among Biological Fathers. Child Maltreatment. 2011; 16: 51-62. PMid:21062788. http://dx.doi.org/10.1177/1077559510385841

[13] Runyan Desmond K. The challenges of assessing the incidence of inflicted traumatic brain injury: a world perspective. American journal of preventive medicine. 2008; 34: S112-S115. PMid:18374259. http://dx.doi.org/10.1016/j.amepre.2008.01.011

[14] Ommaya A, Fass F, Yarnell P. Whiplash injury and brain damage. JAMA. 1968; 204: 75-9. http://dx.doi.org/10.1001/jama.1968.03140170001001

[15] Duhaime AC, Gennarelli TA, Thibault LE, et al. The shaken baby syndrome. A clinical, pathological, and biomechanical study. J Neurosurg. 1987; 66: 409-15. PMid:3819836. http://dx.doi.org/10.3171/jns.1987.66.3.0409

[16] Prange MT, Coats B, Duhaime AC, et al. Anthropomorphic simulations of falls, shakes, and inflicted impacts in infants. J Neurosurg. 2003; 99: 143-50. PMid:12854757. http://dx.doi.org/10.3171/jns.2003.99.1.0143

[17] Lloyd J, Willey EN, Galaznik JG, et al. Biomechanical evaluation of head kinematics during infant shaking versus pediatric activities of daily living. J Forensic Biomech. 2011; 2: 1-9. http://dx.doi.org/10.4303/jfb/F110601

[18] Goldsmith W, Plunkett J. A biomechanical analysis of the causes of traumatic brain injury in infants and children. The American Journal of forensic medicine and pathology. 2004; 25: 89-100. PMid:15166757.

http://dx.doi.org/10.1097/01.paf.0000127407.28071.63

[19] Reece R, Sege R. Childhood Head Injuries: Accidental or Inflicted? Arch Pediatr Adolesc Med. 2000; 154: 11-15. PMid:10632244.

[20] Bandak FA. Shaken baby syndrome: A biomechanics analysis of injury mechanisms. Forensic Science International. 2005; 151: 71-9. PMid:15885948. http://dx.doi.org/10.1016/j.forsciint.2005.02.033

[21] Molina DK. Neck Injuries and Shaken Baby Syndrome. The American Journal of Forensic Medicine \& Pathology. 2009; 30(1): 89-90. PMid:19237866. http://dx.doi.org/10.1097/PAF.0b013e31818737d2 
[22] Atwal GS, Rutty GN, Carter N, et al. Bruising in non-accidental head injured children; a retrospective study of the prevalence, distribution and pathological associations in 24 cases. Forensic Sci Int. 1998; 96: 215-30. http://dx.doi.org/10.1016/S0379-0738(98)00126-1

[23] Case Mary E, et al. Position paper on fatal abusive head injuries in infants and young children. The American journal of forensic medicine and pathology. 2001; 22: 112-22. http://dx.doi.org/10.1097/00000433-200106000-00002

[24] Mack J, Squier W, Eastman JT. Anatomy and development of the meninges: implications for subdural collections and CSF circulation. Pediatric radiology. 2009; 39: 200-10. PMid:19165479. http://dx.doi.org/10.1007/s00247-008-1084-6

[25] Geddes JF, Hackshaw AK, Vowles GH, et al. Neuropathology of inflicted head injury in children. I. Patterns of brain damage. Brain. 2001; 124: 1290-98. PMid:11408324. http://dx.doi.org/10.1093/brain/124.7.1290

[26] Geddes JF, Vowles GH, Hackshaw AK, et al. Neuropathology of inflicted head injury in children. II. Microscopic brain injury in infants. Brain. 2001; 124: 1299-1306. PMid:11408325. http://dx.doi.org/10.1093/brain/124.7.1299

[27] Geddes JF, Tasker RC, Hackshaw AK, et al. Dural haemmorhage in non-traumatic infant deaths: does it explain the bleeding in ‘shaken baby syndrome?’ Neuropathol Appl Neurobiol. 2003; 29: 14-22. PMid:12581336. http://dx.doi.org/10.1046/j.1365-2990.2003.00434.x

[28] Cohen MC, Scheimberg I. Evidence of occurrence of intradural and subdural haemorrhage in the perinatal and neonatal period in the context of hypoxic ischaemic encephalopathy: an observational study from two referral institutions in the United Kingdom. Pediatric and Developmental Pathology. 2009; 12: 169 -176. PMid:19007301. http://dx.doi.org/10.2350/08-08-0509.1

[29] Scheimberg I, Cohen MC, Zapata Vazquez RE, et al. Non-traumatic intradural and subdural haemorrhage and hypoxic ischaemic encephalopathy in fetuses, infants and children up to 3 years of age. Analysis of two audits of 636 cases from two referral centers in the United Kingdom. Pediatr Dev Pathol. 2013; 16: 149-159. PMid:23113698. http://dx.doi.org/10.2350/12-08-1232-OA.1

[30] McQuillen PS, Barkovich J, Hamrick S, et al. Temporal and Anatomic Risk Profile of Brain Injury With Neonatal Repair of Congenital Heart Defects Stroke. 2007; 38; 736-41.

[31] Barnes, et al. Infant Acute Life-Threatening Event-Dysphagic Choking Versus Nonaccidental Injury. Semin Pediatr Neurol. 2010; 17: 7-12. PMid:20434683. http://dx.doi.org/10.1016/j.spen.2010.01.005

[32] David TJ. Non-accidental head injury - the evidence. Pediatr Radiol. 2008; 38 (Suppl 3): S370-S377. PMid:18470445. http://dx.doi.org/10.1007/s00247-008-0829-6

[33] Lantz PE. Postmortem detection and evaluation of retinal hemorrhages. Abstract, presented at the AAFS Annual meeting. Seattle, Washington, February, 2006. Am Acad Forens Sci 2006

[34] Barnes P. Imaging of Nonaccidental Injury and the Mimics: Issues and Controversies in the Era of Evidence-Based Medicine. Radiological Clinics of North America. 2011; 49: 205-229. PMid:21111136. http://dx.doi.org/10.1016/j.rcl.2010.08.001

[35] Wiedman M, Geoffrey CT. High-altitude retinopathy and altitude illness. Ophthalmology. 1999; 106: 1924-1927. http://dx.doi.org/10.1016/S0161-6420(99)90402-5

[36] http://ruthinjustice.org/crow.htm

[37] Miller R, Miller ME. Overrepresentation of males in traumatic brain injury of infancy and in infants with macrocephaly: Further evidence that questions the existence of shaken baby syndrome. American Journal of Forensic Medicine and Pathology. 2010; 31: 165-173. PMid:20308871. http://dx.doi.org/10.1097/PAF.0b013e3181d96a8e

[38] Krasnokutsky M. Cerebral venous thrombosis: A potential mimic of primary traumatic brain injury in infants. American Journal of Radiology. 2011; 197: W503-W507. http://dx.doi.org/10.2214/ajr.10.5977

[39] Miller D, Barnes P, Miller ME. The significance of macrocephaly or enlarging head circumference in infants with the triad: Further evidence of mimics of shaken baby syndrome. American Journal of Forensic Medicine and Pathology. 2015; 36: 111-120. PMid:25893912. http://dx.doi.org/10.1097/PAF.0000000000000152

[40] Plunkett J. Fatal pediatric head injuries caused by short distance falls. American Journal of Forensic Medicine and Pathology. 2001; 22: 1-12. PMid:11444653. http://dx.doi.org/10.1097/00000433-200103000-00001

[41] Prologue - Menkes disease mimicking SBS. http://onsbs.com/prologue/

[42] Dias MS, Smith K, Mazur P, et al. Preventing abusive head trauma among infants and young children: a hospital-based, parent education program. Pediatrics. 2005; 115: 470-7. PMid:15805350. http://dx.doi.org/10.1542/peds.2004-1896

[43] http://www.ncsl.org/research/human-services/shaken-baby-syndrome-prevention-legislation.aspx

[44] Shannon M, Zolotor A, Parrish J, et al. National, regional and state abusive head trauma: Application of the CDC algorithm. Pediatrics. 2013; 132: e1546-e1553.

[45] http://www.cdc.gov/traumaticbraininjury/data/rates.html

[46] Keenan Heather T, et al. A population-based study of inflicted traumatic brain injury in young children. JAMA. 2003; 290: 621-6. PMid:12902365. http://dx.doi.org/10.1001/jama.290.5.621 
[47] Miller, Marvin. Letter to Editor. Incidence of inflicted traumatic brain injury in infants. JAMA. 2003; $290: 2542-2543$. PMid:14625325. http://dx.doi.org/10.1001/jama.290.19.2542-b

[48] Barlow Karen M, Robert AM. Annual incidence of shaken impact syndrome in young children. The Lancet. 2000; 356: $1571-72$. http://dx.doi.org/10.1016/S0140-6736(00)03130-5

[49] Miller ME. Letter to Editor. Shaken impact syndrome. The Lancet. 2001; 357: 1207. http://dx.doi.org/10.1016/S0140-6736(00)04354-3

[50] Guthkelch AN. Infantile subdural hematoma and its relationship to whiplash injuries. Brit Med J. 1971; 2: 430-1. PMid:5576003. http://dx.doi.org/10.1136/bmj.2.5759.430

[51] Caffey J. The whiplash shaken infant syndrome: manual shaking by the extremities with whiplash- induced intracranial and intraocular bleedings, linked with residual permanent brain damage and mental retardation. Pediatrics. 1974; 54: $396-403$. PMid:4416579.

[52] Kempe CH, Silverman FN, Steele BF, et al. The battered-child syndrome. JAMA. 1962; 181: 17-24. PMid:14455086. http://dx.doi.org/10.1001/jama.1962.03050270019004

[53] Donohoe M. Evidence-based medicine and shaken baby syndrome. Part 1: literature review. 1966-1998. Am J Forensic Med Pathol. 2003; 24: 239-242. PMid:12960659. http://dx.doi.org/10.1097/01.paf.0000083635.85457.97

[54] Acres MJ, Morris JA. The pathogenesis of retinal and subdural haemorrhages in non-accidental head injury in infancy: Assessment using Bradford Hill criteria. Medical Hypotheses. 2014; 82: 1-5. PMid:24139052. http://dx.doi.org/10.1016/j.mehy.2013.09.017 